\title{
SELF-INFLICTED FIREARM INJURIES AS COMPARED TO THE ACCIDENTAL FIREARM INJURY; A COMPARATIVE ANALYTICAL STUDY TO DETERMINE THE COMMONEST SITE OF NON-SUICIDAL SELF-INFLICTED INJURIES
}

\author{
Syed Shehzad Husnain, Syed Taokeer Ahmed Rizvi, Imran Ashraf, Romesa Qaiser Khan, Waseem Khan Niazi*, Ali Shan Rao \\ Combined Military Hospital Kharian/National University of Medical Sciences (NUMS) Pakistan, Pakistan Naval Ship, Shifa Hospital, Karachi Pakistan
}

\begin{abstract}
Objective: To determine the commonest site of non-suicidal self-inflicted firearm wound in comparison with accidental firearm wounds.

Study Design: Cross sectional study.

Place and Duration of Study: Combined Military Hospitals Jhelum, Bannu \& Kharian, from Nov 2014 to Nov 2018.

Methodology: Sixty-four patients with firearm injuries were observed. All the participants were males between the ages of $18-$ 60 years. The injuries were determined to be either self-inflicted or accidental by an independent committee. The participants' replies and responses were assessed by dividing them into five main domains by using quantitative software SPSS version 20. Variables involving demographic characteristics of participants such as age, occupation, marital and socioeconomic status, were associated with mental health variables such as psychological stress, previous history of self-harm and clinical psychiatric illness.

Result: Fifteen subjects were found to have self-inflicted injuries and 50 had accidental injuries. There was a marked preference for left foot and left lower limb as a site for non-suicidal self-inflicted injuries (94.6\%) as compared to other sites (left upper extremity $1.8 \%$, chest $1.8 \%$ and right lower extremity $1.8 \%$ ).

Conclusions: Left lower limb and left foot was a more common site for self-injury as compared to the other sites.
\end{abstract}

Keywords: Accidental, Firearms, Non-suicidal, Self-inflicted.

How to Cite This Article: Husnain SS, Rizvi STA, Ashraf I, Khan RQ, Niazi WK, Rao AS. Self-Inflicted Firearm Injuries as Compared To The Accidental Firearm Injury; A Comparative Analytical Study to Determine The Commonest Site of non-Suicidal Self-Inflicted Injuries. Pak Armed Forces Med J 2021; 71(6): 1937-1940. Doi: https://doi.org/10.51253/pafmj.v6i6.3316

This is an Open Access article distributed under the terms of the Creative Commons Attribution License (https://creativecommons.org/licenses/by-nc/4.0/), which permits unrestricted use, distribution, and reproduction in any medium, provided the original work is properly cited.

\section{INTRODUCTION}

Non-suicidal self-injury (NSSI) is a recent diagnostic term used to define behavior where a person self-harms without suicidal intent. It differentiates between someone who is not suffering from a psychotic disorder and someone who is, and even between patterns of injury in terms of inflicting one lethal injury versus infliction of several non-fatal mutilations repeatedly. ${ }^{1}$ Accidental firearm injuries manifest as widely spread skeletal injuries when compared with self-inflicted injuries having non-suicidal intent which have a localized pattern. Causes of accidental firearm injuries may include personal or mechanical errors such as failure to perform normal safety procedure (NSP) before, during or after handling a weapon, use of firearms in closed spaces which increases the possibility of ricochet, inexperienced user and/or faulty weapon itself. ${ }^{2}$

Self-inflicted injuries may lead to handicap in otherwise healthy individual and carry considerable mortality and morbidity as well. Such injuries have an

Correspondence: Dr Syed Shehzad Husnain, Department of Surgery, Combined Military Hospital Kharian Pakistan

Received: 30 Sep 2019; revision received: 21 Apr 2021; accepted: 04 May 2021 extensive social, emotional, and economic impact on those affected, including their family, friends and the community. These cases also require emergency treatment, hospitalization and long-term care; hence costly healthcare resources have to be channelized from other priorities towards their management. ${ }^{3}$ Their management appears as a considerable challenge and demands an interdisciplinary course of action requiring cooperation and teamwork of the surgeon, anesthetist, rehab specialist and psychiatrist. The surgeon evaluates and fixes damaged and severed tissues to restore anatomy and function. The anesthetist secures patient's airway and breathing; the rehab specialist ensures recovery of limb function while the psychiatrist provides adequate mental and emotional care as well as supervision during and after surgical treatment, ${ }^{4}$ However, in most developing countries late presentation to the hospital, lack of adequate management in ambulance and poor pre-hospital care predisposes to increased morbidity and mortality. ${ }^{5}$

Many published reports are from developed countries where there are multiple studies on self-inflicted injuries, their risk factors and the socioeconomic 
impact of self-harm. ${ }^{6}$ Whereas in underdeveloped or developing countries, self-inflicted injuries are not given priority because there is greater emphasis on trauma related to RTA as road traffic accidents are a major contributor to annual mortality. ${ }^{7}$ When discussing intentional versus firearm injuries, several patterns of injury, site and types have been proposed. Factors that need to be kept into consideration include the triad of the environment (socio-economic environment, income disparity, and peer pressure), the individual (stability of mental health, previous behavioral patterns, personal nutrition) and the infrastructure (availability of healthcare resources, monitoring of at-risk groups and preventive counseling measures). All these factors can shape the pattern, type and extent of injury due to their interaction. 8,9 Therefore, there is a need to further assess how the demographic characteristics of affected individuals are related to patterns of injury. A more comprehensive study is required in this field, taking into consideration the risk of injury (like stress, multiple tours \& homesickness), frequency of selfharm, type of injury and the cultural factors in order to provide a comprehensive picture of accidental and intentional injury patterns.

\section{METHODOLOGY}

This was a cross sectional study, taking sample of 64 patients. The study was conducted at Combined Military Hospitals Jhelum, Bannu \& Kharian to describe the experience and management of non-suicidal self-inflicted versus accidental firearms injuries, outlining the patterns of injury sites, source and anatomical preference of these injuries. Non-probability consecutive sampling technique was used. Institutional consent was taken with Ref No. 1100/Adm dated 16 April 2021. CMH Kharian and informed consent was obtained. The injuries were determined to be either selfinflicted or accidental by an independent committee. Post-operative data was collected from the patients who had undergone surgery.

Inclusion Criteria: Individuals between the ages of 1860 years, without comorbidity, and were able to speak and understand Urdu, Pashto and/or English were included in the study.

Exclusion Criteria: Patients who had more than one gunshot wound, or who had a previous gunshot wound within the past one year were excluded.

Data was collected using scale of self-inflicted firearm injury (SIFI), ${ }^{10-11}$ and few open ended queries. A sample of 64 male respondent was recruited in this study. The bracketing was taken care of throughout the procedures of data collection. Statistical Package for the social sciences (SPSS) version 20 was used for the data analysis purpose. The results obtained were categorized into four main categories that describe the patient's self-inflicted injuries these categories are designed on the bases of patient (i) age (ii) site of injury (iii) presence of witnesses (iv) yearning for speedy recovery. Frequency and percentage were calculated for qualitative variables.

\section{RESULTS}

A sample of 64 male patients was included. Mean age was $40.23 \pm 9.35$ years (range 18-60 years). The individuals in the younger age group were emotionally immature as compared to older individuals who were more emotionally stable and this led to decreased number of injuries in elder patients. The individuals who harmed themselves chose the site of harm carefully. They usually selected the site that was non-lethal. The choice of site was also dependent on minimum handicap. The individuals who did self-harm usually did so in the absence of any witnesses. Accidental injuries were in the presence of two or more than two witnesses who could prove that the injuries were accidental. The individuals chose those sites for self-harm from where the recovery was easy and chose such timing that the recovery from the injury site was quick. The total proportion of accidental versus self-inflicted injuries were given in the Table, which indicated accidental gunshots were $52(81.25 \%)$. The highest number of wounds in a single site was left leg and left arm.

\begin{tabular}{l|c|c|c|c}
\multirow{2}{*}{ Table-I: Site of gunshot wound. } \\
\cline { 2 - 5 } Site & \multicolumn{2}{|c|}{ Accidental } & \multicolumn{2}{c}{ Self-inflicted } \\
\hline Chest & $5(9.6)$ & $\begin{array}{c}\text { Left } \\
\text { Cord/Bal } \\
=2(3.8)\end{array}$ & Right & Left \\
\cline { 1 - 4 } Abdomen & $7(13.4)$ & - & $\begin{array}{c}\text { Sord/Back) } \\
=-\end{array}$ \\
\hline Thigh & $5(9.6)$ & $3(5.7)$ & - & - \\
\hline Leg & $3(5.7)$ & $8(15.4)$ & - & $6(9.2)$ \\
\hline Foot & $4(7.6)$ & $2(3.8)$ & $1(1.5)$ & $3(4.6)$ \\
\hline Arm & $3(5.7)$ & $8(15.4)$ & - & - \\
\hline Forearm & - & $1(1.9)$ & - & - \\
\hline Hand & - & $1(1.9)$ & - & $1(1.5)$ \\
\hline Total & \multicolumn{2}{|c|}{$52(81.25)$} & \multicolumn{2}{c}{$12(18.75)$} \\
\hline
\end{tabular}

\section{DISCUSSION}

The study was conducted to observe the self-inflicted injuries, self-inflicted injuries showed a distinct pattern as compared to accidental injuries. The result of the study showed that accidental injuries involved either multiple sites or random ones; self-injuries showed deliberation was involved in choosing the site of injury and were clustered over a very small anatomical 
area. Most participants who had inflicted these injuries were married, under stress of active duty and hoping to gain time off and associated benefits from the workplace. They were also conscious of choosing sites that afforded them the greatest mobility, least possibility of serious complications and earliest recovery.

Majority $(80 \%)$ belonged to a low socioeconomic background and almost $60 \%$ were married. A significant proportion $(30 \%)$ gave a history of previous selfharm and had other psychosomatic complaints. A history of previous psychiatric illness could not be obtained due to the stigma surrounding a clinical diagnosis of mental illness but patients objectively admitted to having depressive symptoms and suboptimal functioning in daily life.

All these variables contributed significantly to the respondent's decision to self-harm, but did not impair the deliberation of the injury site and consequences of said injury. Most self-inflicting respondents chose left leg as the site of injury due to being right handed $(94 \%)$ and due to greater ease of access to injury site (left leg) minimizing the possibility of stray bullet injury or ricochet.

In comparison, abdomen and chest were significant sites for accidental injury $10 \%$ and $13 \%$ respectively. With the exception of right arm and right hand, all body sites were involved, recovery was complicated and recovery time was prolonged. There was significant restriction in movement and patients' main concern was prevention of mortality rather than early recovery.

Self-inflicted injuries are distinct from accidental injuries in their manifestation and ideation. These injuries have unique identifiers that can aid in their speedy identification and subsequent management. ${ }^{12-16}$ Selfinfliction is a full-fledged diagnostic category for DSM$5 . .^{17,18}$ In our study, this signature "identifier" is a predominance of left-sided lower limb gunshot wounds in right-handed personnel.

Self-injuries constitute a growing but neglected epidemic in developing countries and contribute significantly to the global injury burden. In this study, most patients were males in their 20s and 30s. The question then arises of why such behavior prevails. Male predominance in this age group may be attributable to their active participation in risk taking behaviors and their frequent involvement in substance abuse in some areas. ${ }^{11}$ Previous studies regarding self-inflicted injuries have shown that a history of a previous self-inflicted injury is a key risk factor for a repeat episode.
Similarly, psychiatric illness has also been reported to one of the strongest predictors of self-inflicted injuries. 12 Other predictors are comorbidities, terminal illness, poor quality of life or the prospect of receiving undue benefits. ${ }^{13}$

Our recommendation is that there should be the introduction of a screening system to identify at-risk persons using these predictors, a compulsory counseling service that can address these concerns when they are identified and a monitoring body that follows up on the prognosis of such cases. An internal audit of such behavioral patterns and the reasons for their occurrence can be greatly cost effective in terms of both manpower and healthcare resources utilized.

\section{CONCLUSION}

Left lower limb and left foot was a more common site for self-injury as compared to the other sites.

\section{Conflict of Interest: None.}

\section{Authors' Contribution}

SH: Direct contribution of conception of study, STAR: Direct contribution of conception of study, IA: Intellectual contribution of conception of study, RQK: Intellectual contribution of conception of study, WKN: Intellectual contribution of conception of study, ASR: Intellectual contribution of conception of study.

\section{REFERENCES}

1. Angelotta C. Defining and Refining Self-Harm. J Nerv Ment Dis 2015; 203(2): 75-80.

2. Lee RK, Harris MJ. Unintentional Firearm Injuries: The Price of Protection. Am J Prev Med 1993; 9(3): 16-20.

3. Matzopoulos R, Bowman B, Butchart A, Mercy JA. The impact of violence on health in low- to middle-income countries. Int J Inj Contr Saf Promot 2008; 15(4): 177-187.

4. Lichte P, Oberbeck R, Binnebösel M, Wildenauer R, Pape HC, Kobbe P. A civilian perspective on ballistic trauma and gunshot injuries. Scand J Trauma Resusc Emerg Med 2010; 18(1): 35-38.

5. Alibhai A, Hendrikse C, Bruijns SR. Poor access to acute care resources to treat major trauma in low- and middle-income settings: A self-reported survey of acute care providers. African J Emerg Med Rev 2019; 9(Suppl-1): S38-S42.

6. Livingston DH, Lavery RF, Lopreiato MC, Lavery DF, Passannante MR. Unrelenting violence. J Trauma Acute Care Surg 2014; 76(1): 2-11.

7. Nantulya VM, Reich MR. The neglected epidemic: road traffic injuries in developing countries. BMJ 2002; 324(7346): 1139-1141.

8. Wintemute GJ. The Epidemiology of Firearm Violence in the Twenty-First Century United States. Annu Rev Public Health 2015; 36(1): 5-19.

9. Guetschow B, Lilienthal M, Willey M. Unintentional Firearm Injuries Remain Prevalent Over a 12 Year Experience at a Rural Midwestern Level 1 Trauma Center. Iowa Orthop J 2018; 38(2): 45-52.

10. Sornberger MJ, Heath NL, Toste JR, McLouth R. Nonsuicidal Self-Injury and Gender: Patterns of Prevalence, Methods, and Locations among Adolescents. Suicide Life-Threatening Behav 2012; 42(3): 266-278. 


\section{Non-Suicidal Self-Inflicted Injuries}

11. Menninger KA. Man against himself. New York: Harcourt Brace \& World; 1938

12. Moore GM, Plew JD, Bray KM, Snars JN. Survivors of selfinflicted firearm injury. Med J Aust 1994; 160(7): 421-425.

13. Haw C, Hawton K. Psychiatric and personality disorders in deliberate self-harm patients. Br J Psychiatr 2001; 178(1): 48-54.

14. Wichstrim L. Predictors of non-suicidal self-injury versus attempted suicide: similar or different? Arch Suicide Res 2009; 13(2): 105-122.

15. Betz ME, Wintemute GJ. Physician counseling on firearm safety. J Am Med Assoc 2015; 314(5): 449.
16. American Psychiatric Association. Diagnostic and statistical manual of mental disorders. America Psychiatric Publishing. Washington DC; $5^{\text {th }}$ ed; 2013, https://libguides.kpu.ca/psy/ DSM?gclid=Cj0KCQiA2ZCOBhDiARIsAMRfv9IhAp6lNUhh99x w2YCd61hs_pdyPIQK1lg_DMf4MVOyyDEAiOFWjMaAky5EALw_wcB

17. Gilman SL. How new is self-harm? J Nerv Ment Dis 2012; 200(1): 1008-1016.

18. Gilman SL. From psychiatric symptom to diagnostic category: self-harm from the Victorians to DSM-5. Hist Psych 2013; 24(2): 148-165. 